\title{
Successful Delivery at 37 Weeks via C-Section and Simultaneous Total Hysterectomy, After IVF Oocytes Donor Transfer in an Ovarian Cancer Patient
}

\author{
Orestis Tsonis $^{1 *}$, Minas Paschopoulos ${ }^{1}$ and Fani Gkrozou ${ }^{2}$ \\ ${ }^{1}$ Department of Obstetrics and Gynaecology, Medical School, University of Ioannina, Ioannina, Greece \\ ${ }^{2}$ Department of Obstetrics and Gynaecology, University Hospitals of Birmingham, United Kingdom
}

*Corresponding author: Orestis Tsonis, Department of Obstetrics and Gynaecology, Medical School, University of Ioannina, Ioannina, Greece; Email: orestis.tsonis@ gmail.com

Received: February 25, 2019; Accepted: March 11, 2019; Published: April 20, 2019;

\begin{abstract}
A salpingo-oophorectomy due to an ovarian malignancy could be accompanied with great stress and a number of risks for childless but, still fertile women. This situation poses a great challenge for an obstetrical point of view. A successful twin pregnancy at 37 weeks via c-section with simultaneous total hysterectomy is reported to a woman who was diagnosed with ovarian cancer (sex cord granulose tumor) and treated with right salpingooophorectomy 3 years prior to a successful fourth trial of IVF implantation. This woman underwent a c-section at 37 weeks, giving birth to twin females neonates with a simultaneous total hysterectomy. Antenatally, no complications were reported, rather than an admission due to premature contractions at $26+3$, which resolved with adequate medication 5 days later, when the patient was fit for discharge and appointed for the operation. Her postoperative course was uneventful.
\end{abstract}

\section{Introduction}

Infertility causes a great deal of stress to a large number of women all over the world. Imaging complicates an already complex situation with the presence of ovarian cancer. Time limits become narrower and the obstetric team needs to evaluate and assess the risk of cancer versus the risk of failure in conception. Ovarian sex cord-stromal tumors (SCSTs) are extremely rare with a favorable long-term prognosis [1]. These types of ovarian cancer results to $7 \%$ of the all ovarian tumors [2]. For the reasons above, fertility sparing technique should be encouraged. Since the majority of women affected are young and at a reproductive age the safety of fertility-sparing operations must be assessed [3]. More specifically, GCTs illustrate a 5-year-survival prognosis of $92 \%$ to $100 \%$ in cases of surgical staging $[4,5]$.

\section{History}

A 40 -yer-old gravida 1 para 0 with a history of thrombophilia (antithrombin III deficiency) underwent a laparoscopy due to a cyst foun via ultrasound suring her preIVF assessment in late 2014. Due to the size of the cyst, the specimen had to be resected in order to be removed through the trocar openings. The pathologist review revealed a sex cord ovarian tumor-granulosa cell tomor (GCT) stage IC. The stage of the tumor was possibly overestimated since the resected specimen could not provide to the pathologist clear limits for staging. After 2 months, the patient underwent an open surgery removal of right adnexa, appendicectomy and omentomectomy. No chemotherapy was proposed. In addition, she received IVF with 2 cycles of citric clomifaine ovarian hyperstimulation without any result since she had an incident of miscarriage at 8 weeks. Another 2 courses of treatment with donor ovarian foccicles were perfomed. The first led to a miscarriage at 5 weeks but the latest led to success with 2 MCDA twin female embryos. During her pregnancy no pathology was noted. At $26+3$ weeks she was admitted in the hospital due to premature contractions for which she received 2 courses of Atosiban till 27+4 weeks. At $27+5$ she was discharged by the hospital and she was appointed for a ceasearian section at 37 weeks with a simultaneous hysterectomy and left salpingo-ophorectomy. The perinatal outcome was successful resulting to twin healthy females neonates with an Apgar score 10 out of 10 within the first minute of their birth and adequate weight. They required no incubators.

\section{Literature Review}

Fertility-sparing operation has been proposed in order to achieve a viable pregnancy for women who are younger and usually present with early stages of cancer [6]. Nevertheless, the risk of recurrence is high, almost $45 \%$ in cases of cystectomy which means that fertility methods must work in a timely manner $[6,7]$. In this case no chemotherapy was proposed, since international literature suggests platinum-based chemotherapy in cases of advanced ovarian cancer or recurrent disease [8].

Due to the rarity of this GCTs, no large scale randomized trials have been conducted, leaving a vague approach in cases, where fertility must be preserved $[9,10]$. However, it seems that women at stage I have a very low risk of further recurrence, when adequate surgical staging has been performed [3]. Further investigation in 
literature reveals a unexpected increased female neonates ratio as well as a full term births for women in pregnancies complicated with SCTs [11]. Usually after delivery, a second operation must be perform [12, 13]. Total hysterectomy with bilateral salpingo-oophorectomy must be performed \pm chemotherapy [14].

\section{Conclusion}

The evolution of obstetrics and gynecology even in severe cases such as ovarian cancer, gives women, who wish to maintain their fertility, many options. In this case, this patient not only was treated for ovarian cancer, patient's fertility was preserved for further pregnancy. IVF treatment was successful and the obstetrics team achieved an appointed birth via c-section at 37 weeks despite all odds.

\section{Discussion}

For complicated cases as the one presented above, a multidisciplinary team must be sought [15-17]. The need for a collaboration of an obstetrician, a pediatrician, an oncologist and a pathologist is self-explanatory [18]. Platinum -based chemotherapy should be sought since the stage of the ovarian tumor is higher than I. (see figure 1 below) [19].

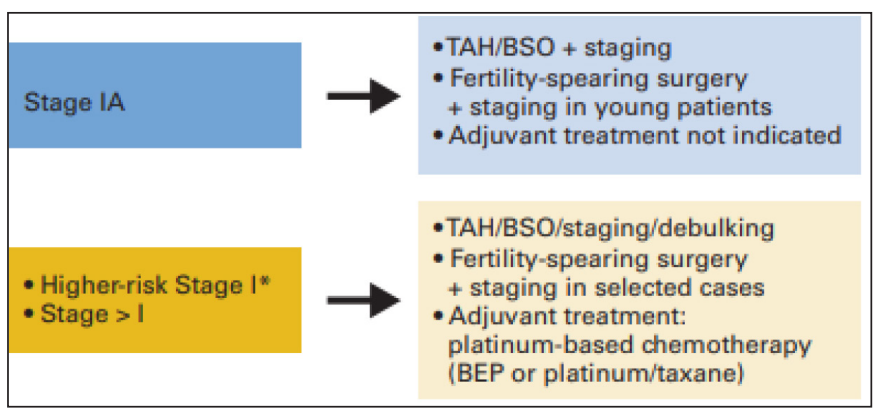

Authors have no conflict of interest.

\section{References}

1. Serov SF, Scully RE, Sobin LH (1973) Histological typing of ovarian tumours: Citeseer.

2. Koonings PP, Campbell K, Mishell JD, Grimes DA (1989) Relative frequency of primary ovarian neoplasms: a 10-year review. Obstetrics and Gynecology 74: 921-926.

3. Evans AT 3rd, Gaffey TA, Malkasian GD Jr, Annegers JF (1980) Clinicopathologic review of 118 granulosa and 82 theca cell tumors. Obstet Gynecol 55: 231-238. [crossref]

4. Malmström H, Högberg T, Risberg B, Simonsen E (1994) Granulosa cell tumors of the ovary: prognostic factors and outcome. Gynecologic oncology 52: 50-55.

5. Zhang M, Cheung MK, Shin JY (2007) Prognostic factors responsible for survival in sex cord stromal tumors of the ovary-an analysis of 376 women. Gynecologic oncology 104: 396-400.

6. Cadron I, Leunen K, Van Gorp T, Amant F, Neven P, et al. (2007) Management of borderline ovarian neoplasms. Journal of clinical oncology 25: 2928-2937.

7. Marret H, Lhommé C, Lecuru F (2010) Guidelines for the management of ovarian cancer during pregnancy. European Journal of Obstetrics \& Gynecology and Reproductive Biology 149: 18-21.

8. Colombo N, Parma G, Zanagnolo V, Insinga A (2007) Management of ovarian stromal cell tumors. J Clin Oncol 25: 2944-2951. [crossref]

9. Gershenson DM (2005) Fertility-sparing surgery for malignancies in women. J Natl Cancer Inst Monogr 43-47. [crossref]

10. Morice P, Denschlag D, Rodolakis A (2011) Recommendations of the Fertility Task Force of the European Society of Gynecologic Oncology about the conservative management of ovarian malignant tumors. International Journal of Gynecological Cancer 21: 951-963.
11. Blake EA, Carter CM, Kashani BN (2014) Feto-maternal outcomes of pregnancy complicated by ovarian sex-cord stromal tumor: a systematic review of literature. European Journal of Obstetrics \& Gynecology and Reproductive Biology 175: 1-7.

12. Young RH, Dudley AG, Scully RE (1984) Granulosa cell, Sertoli-Leydig cell, and unclassified sex cord-stromal tumors associated with pregnancy: a clinicopathological analysis of thirty-six cases. Gynecologic oncology 18: 181-205.

13. Behtash N, Zarchi MK, Gilani MM, Ghaemmaghami F, Mousavi A, et al. (2008) Ovarian carcinoma associated with pregnancy: a clinicopathologic analysis of 23 cases and review of the literature. BMC pregnancy and childbirth 8: 3 .

14. Zhao X, Huang H, Lian L, Lang J (2006) Ovarian cancer in pregnancy: a clinicopathologic analysis of 22 cases and review of the literature. International Journal of Gynecological Cancer 16: 8-15.

15. Bernhard LM, Klebba PK, Gray DL, Mutch DG (1999) Predictors of persistence of adnexal masses in pregnancy. Obstet Gynecol 93: 585-589. [crossref]

16. Wong H, Low J, Chua Y, Busmanis I, Tay E, et al. (2007) Ovarian tumors of borderline malignancy: a review of 247 patients from 1991 to 2004. International Journal of Gynecological Cancer 17: 342-349.

17. Amant F, Van Calsteren K, Halaska MJ (2011) Gynecologic cancers in pregnancy: guidelines of an international consensus meeting. Rare and Uncommon Gynecological Cancers: Springer 209-227.

18. Sherard GB 3rd, Hodson CA, Williams HJ, Semer DA, Hadi HA, et al. (2003) Adnexal masses and pregnancy: a 12-year experience. Am J Obstet Gynecol 189: 358-362. [crossref]

19. Schneider DT, Calaminus G, Wessalowski R, Pathmanathan R, Selle B, et al. (2003) Ovarian sex cord-stromal tumors in children and adolescents. J Clin Oncol 21: 2357-2363. [crossref]
Citation:

Orestis Tsonis, Minas Paschopoulos and Fani Gkrozou (2019) Successful Delivery at 37 Weeks via C-Section and Simultaneous Total Hysterectomy, After IVF Oocytes Donor Transfer in an Ovarian Cancer Patient. Integr Gyn Obstet $J$ Volume 2(2): 1-2. 